\title{
Effect of Critical Illness Insurance on Household Catastrophic Health Expenditure: The Latest Evidence from the National Health Service Survey in China
}

\author{
Anqi Li ${ }^{1}$, Yeliang Shi ${ }^{1}$, Xue Yang ${ }^{1}$ and Zhonghua Wang ${ }^{1,2,3, *(1)}$ \\ 1 School of Health Policy Management, Nanjing Medical University, Nanjing 211166, China; \\ lianqi_njmu@163.com (A.L.); 2004azure@163.com (Y.S.); njmuyangxue@163.com (X.Y.) \\ 2 Creative Health Policy Research Group, Nanjing Medical University, Nanjing 211166, China \\ 3 Center for Global Health, Nanjing Medical University, Nanjing 211166, China \\ * Correspondence: wzh04@njmu.edu.cn; Tel.: +81-025-868-682-58
}

Received: 13 November 2019; Accepted: 11 December 2019; Published: 13 December 2019

\begin{abstract}
Background: China fully implemented the critical illness insurance (CII) program in 2016 to alleviate the economic burden of diseases and reduce catastrophic health expenditure (CHE). With an aging society, it is necessary to analyze the extent of CHE among Chinese households and explore the effect of CII and other associated factors on CHE. Methods: Data were derived from the Sixth National Health Service Survey (NHSS, 2018) in Jiangsu Province. The incidence and intensity of CHE were calculated with a sample of 3660 households in urban and rural areas in Jiangsu Province, China. Logistic regression and multiple linear regression models were used for estimating the effect of CII and related factors on CHE. Results: The proportion of households with no one insured by CII was $50.08 \%$ (1833). At each given threshold, from $20 \%$ to $60 \%$, the incidence and intensity were higher in rural households than in urban ones. CII implementation reduced the incidence of CHE but increased the intensity of CHE. Meanwhile, the number of household members insured by CII did not affect CHE incidence but significantly decreased CHE intensity. Socioeconomic factors, such as marital status, education, employment, registered type of household head, household income and size, chronic disease status, and health service utilization, significantly affected household CHE. Conclusions: Policy effort should further focus on appropriate adjustments, such as dynamization of $\mathrm{CII}$ lists, medical cost control, increasing the CII coverage rate, and improving the reimbursement level to achieve the ultimate aim of using CII to protect Chinese households against financial risk caused by illness.
\end{abstract}

Keywords: critical illness insurance; household; catastrophic health expenditure; incidence and intensity

\section{Introduction}

In response to the call of the World Health Organization (WHO) and to promote population health status, many countries are exerting effort to achieve universal health coverage (UHC), which is a major Sustainable Development Goal. Achieving UHC means that all people receive essential health services without being exposed to financial hardship [1]. Since 2003, China has introduced and implemented a comprehensive package of basic medical insurance (BMI). The BMI system consists of urban employee basic medical insurance, urban resident medical insurance (URMI), new rural cooperative medical scheme (NRCMS), and the urban and rural medical assistance system. These basic medical insurance plans cover about $97 \%$ of the population (over 1.3 billion Chinese), which enabled China to achieve near UHC [2]. 
Despite nationwide coverage, the service provisions and financial protection of the Chinese BMI system are far from sufficient. The risk of various critical diseases (e.g., malignant tumor, acute myocardial infarction, coronary artery diseases, cerebral stroke, etc.) and their economic burden are dramatically increasing with an aging society. Critical illness caused 36.19 million deaths and 662.71 million years of life lost worldwide in 2016 [3]. The Global Burden of Disease Study 2017 also shows that non-communicable diseases accounted for $73.4 \%$ of deaths [4]. In China, mortality due to malignant tumor, cerebral vascular disease, heart disease, and respiratory system disease accounts for $80 \%$ of all deaths. Furthermore, high out-of-pocket costs for treating these critical illnesses can easily impoverish patients and their households. The economic burden of chronic diseases is as high as 2.6 trillion in China [5], and more than $40 \%$ of 72 million poor people re-entered poverty because of diseases in 2016 [6]. Healthcare expenses may overburden patients with critical illnesses, which are often financially devastating for their households. With a limited financial protection effect of the BMI system on reducing catastrophic health expenditure (CHE) in China [7-9], the economic burden of diseases in Chinese households is higher than generally appreciated, and will continue to increase as the population ages [3].

To protect urban and rural residents against large medical expenses and relieve medical expenditure burden, the China central government launched critical illness insurance (CII) in August 2012. It was piloted in more than 134 cities from 2013 and implemented nationally in 2016. CII, also called critical illness insurance for urban and rural residents, covers the enrollee of URMI and NRCMS. It reimburses individuals with critical illnesses for high out-of-pocket healthcare payments (OOP) exceeding a certain level after BMI reimbursement [10]. The central government proposes general guiding principles; for example, the total reimbursement rate is no less than $50 \%$ (adjusted to $60 \%$ in a 2019 government work report [11]) when medical bills for necessary treatments after reimbursement under the BMI system exceed annual per capita income levels. All provincial governments have made detailed rules about the financial mechanism, coverage, and reimbursement with respect to CII. This program does not require an additional premium from the insured; it is mainly funded through BMI surpluses. Therefore, it is an extension and supplement to the Chinese BMI system.

Total OOP equaling or exceeding $40 \%$ of the household capacity to pay (CTP) is considered catastrophic. This definition for CHE proposed by the WHO is widely accepted $[3,12,13]$. The CHE is an important indicator for domestic and foreign researchers to evaluate the effects of medical insurance systems. Many studies have assessed CHE worldwide. Barros et al. [14] estimated catastrophic healthcare expenditure in Brazil using different definitions (including $>40 \%$ of household CTP), and the results indicated that health insurance coverage did not protect from CHE. A systematic review was undertaken by some researchers in Ghana to evaluate whether enrollment in the National Health Insurance Scheme reduces the likelihood of OOP and CHE. They adopted the thresholds of CHE that OOP for healthcare exceeds $20 \%$ of annual household income, $10 \%$ of household expenditures, and $40 \%$ of subsistence expenditures, respectively. Findings suggested that healthcare costs remain catastrophic for a large proportion of insured households in Ghana [15]. Two other studies by Xie et al. [16] and Guo et al. [17] evaluated the role of the Chinese new rural cooperative medical scheme (NRCMS) on protecting households from CHE using $40 \%$ of a household's capacity to pay as the threshold. Both reported that $\mathrm{CHE}$ incidence and intensity decreased after NCMS reimbursement.

Alleviating the economic disease burden and protecting households from CHE were the most important targets of CII [10]. Although local governments have implemented CII for several years, it is far from achieving universal coverage. For example, approximately $50 \%$ of households in Jiangsu Province have not been insured by CII, according to the Sixth National Health Service Survey (NHSS) conducted in Jiangsu Province in 2018. Some studies have researched the implementation effect of CII in China. However, most focused on describing and comparing the design and development of the program policy [18-21] and do not provide strong empirical evidence on the topic. In recent years, several studies performed quantitative analyses. Fang et al. [22] evaluated the effect of CII on the share of medical expenses reimbursed and found that it increases the level of reimbursement to some extent. Zhao et al. [3] indicated that CII is only partially effective in financial risk protection under total 
medical expenses rather than covered medical expenses. Another study [23] focused on the impact of $\mathrm{CII}$ on utilization and costs of hospitalization before and after implementation and found that CII can promote inpatient service utilization but increases patients' economic burden.

All individuals should have access to the health services they need without risk of financial ruin or impoverishment (WHO 2013) [24]. With China's aging society, it is necessary to analyze the effect of $\mathrm{CII}$ on household CHE and economic burden of diseases. To the authors' knowledge, due to a short period of time since broad CII implementation and the lack of empirical data, few studies have assessed the effect of CII on CHE. This study used data from the Sixth National Health Service Survey (2018) to calculate the extent of catastrophic health expenditure in urban and rural households in Jiangsu Province and evaluated the effect of critical illness insurance and associated factors on household catastrophic health expenditure. This study clarifies the implementation effect of its critical illness insurance on financial risk protection in Jiangsu Province; it also provides some significant empirical evidence for reforming China's healthcare insurance.

\section{Materials and Methods}

\subsection{Data Source}

The primary data used in this study were derived from the Sixth NHSS (2018) in Jiangsu Province. The NHSS has been organized by the Chinese National Health Commission every 5 years since 1993, and the Provincial Commission of Health is responsible for the specific survey in their region. The survey aims to understand resident health status and needs for health services in urban and rural China, so as to understand the allocation and utilization of health resources and other information. The sixth NHSS was conducted in 31 provinces in September 2018. According to economical and effective sampling criteria, it used a multistage and stratified cluster sampling method based on administrative region division. With the help of the Center for Health Statistical and Information of National Health Commission, 156 county-level units (counties or urban districts) were sampled, and within each county-level unit, 5 villages and community units were selected as the primary sampling units. Finally, 60 households were selected within every administrative village and community unit using systematic random sampling. The respondents of the survey are the resident population among the sampled households. The resident population refers to all registered and non-registered people who have lived in the household within the past six months. It also includes babies born less than six months old, newly-married spouses, old people supported in turn, and primary and middle school students, but does not include non-family members, such as a nanny. Jiangsu Province is located in the Yangtze River Delta, eastern coast of Mainland China with a population of 80.29 million, $68.76 \%$ and $31.24 \%$ of the residents lived in urban and rural areas, respectively. At the end of 2017, the per capita Gross Regional Product (GRP) of Jiangsu Province was CNY 107150, which was ranked fourth among 31 provinces. The NHSS of Jiangsu Province was conducted in September 2018. Nineteen county-level units were sampled. A number of 11,550 respondents were included. After the elimination of missing individual value, the final household sample size was 3660 .

The questionnaire contents include demographic and socioeconomic characteristics, healthcare services need and utilization, and medical insurances [25]. The questionnaire is structured and has good validity and reliability. Supervisors guided and inspected every step of the survey for quality control. Investigators were trained to conduct qualified face-to-face interviews. District survey managers checked the questionnaires at the end of each day to avoid missing information or logic errors. Moreover, $5 \%$ of all sampled households were randomly selected for revisits to check data accuracy [26]. This study was on a household basis, and most variables were defined in terms of household unit. However, several variables (registered type, marital status, education, employment status) were the characteristics of the head of household. For evaluation accuracy, the variable of BMI was not included in the model because of nearly full coverage in China. Detailed descriptions of variables are shown in Table 1. 
Table 1. Description of explanatory variables.

\begin{tabular}{|c|c|c|}
\hline Variable & Description & Survey Questions \\
\hline \multicolumn{3}{|l|}{ Household Head Variables } \\
\hline Registered Type & $=1$ if registered as rural; $=0$ if registered as urban & Question: What's your registered type? \\
\hline Education Status & $\begin{array}{l}\text { Less than lower secondary/upper secondary vocational } \\
\text { training/tertiary }\end{array}$ & Question: What's your education level? \\
\hline Employment Status & Employed/retired/unemployed & Question: What's your employment status? \\
\hline Marital Status & $=1$ ifmarried; $=0$ if single, widowed, divorced, or other & Question: What's your marital status? \\
\hline \multicolumn{3}{|l|}{ Household Variables } \\
\hline Household Size & Number of persons living together in one house & Number of household members \\
\hline Household CII Status & $=1$ if one or more members have $\mathrm{CII} ;=0$ otherwise & Question: Are you insured by the Critical Illness Insurance? \\
\hline Number of Household Members Having CII & & Number of household members insured by CII \\
\hline Household Income Level & $\leq 30,000 / 30,000-50000 / 50,000-78,500 / 78,500-100,000 /<100,000$ & $\begin{array}{l}\text { Total household income is grouped by quintile. Question: What was } \\
\text { your total household income in the previous year (2017)? }\end{array}$ \\
\hline Household Members with $\geq 2$ Chronic Illness & $\begin{array}{l}=1 \text { if anyone in a household has two or more chronic illnesses; } \\
=0 \text { otherwise }\end{array}$ & $\begin{array}{l}\text { Questions: Do you have confirmed hypertension? Do you have } \\
\text { confirmed diabetes? Do you have other chronic diseases diagnosed? }\end{array}$ \\
\hline Household Members $>65$ Years Old & $=1$ if one or more members $>65$ years old $;=0$ otherwise & Question: Year of birth. \\
\hline Outpatient Utilization Status of Household Members & $\begin{array}{l}=1 \text { if any household member visited a doctor because of any } \\
\text { illness during the past } 2 \text { weeks; }=0 \text { otherwise }\end{array}$ & $\begin{array}{l}\text { Question: Have you seen a doctor because of feeling ill during the } \\
\text { two weeks prior to the survey? }\end{array}$ \\
\hline Inpatient Utilization Status of Household Members & $\begin{array}{l}=1 \text { if any household member hospitalized during the year } \\
\text { before the survey; }=0 \text { otherwise }\end{array}$ & $\begin{array}{l}\text { Question: In the year before the investigation, did you live in a } \\
\text { hospital because of illness, physical examination, delivery, etc? }\end{array}$ \\
\hline Outpatient Service in High-Level Hospital & $\begin{array}{l}=1 \text { if anyone in a household went to a second-level hospital } \\
\text { or above for outpatient treatment; }=0 \text { otherwise }\end{array}$ & $\begin{array}{l}\text { Question: where was your first visit in the two weeks before the } \\
\text { survey? }\end{array}$ \\
\hline Inpatient Service in High-Level Hospital & $\begin{array}{l}=1 \text { if anyone in a household went to a second-level hospital } \\
\text { or above for inpatient treatment; }=0 \text { otherwise }\end{array}$ & $\begin{array}{l}\text { Question: Which of the following medical and health institution are } \\
\text { you hospitalized this time? }\end{array}$ \\
\hline
\end{tabular}

Note: CII, critical illness insurance. 
Among all households included, 54.04\% (1978) were registered as urban and $45.96 \%$ (1682) as rural. The proportion of households that no one insured by CII is $50.08 \%$ (1833), $72.65 \%$ of which were urban households. Regarding demographic classification of household head, $87.27 \%$ were married, $70.03 \%$ had less than lower secondary education, and nearly 30\% were unemployed or retired.

\subsection{Data Analysis}

\subsubsection{Definition}

With regard to the definition of CHE, we followed the one proposed by WHO: OOP is considered as catastrophic if it equals or exceeds $40 \%$ of the household's CTP [27]. CTP is known as non-food household expenditure. Some studies adopt another definition that CHE occurs if OOP comprise $\geq 10 \%$ of total household expenditures. We used the former because subtracting food expenses can partly avoid deviation in measurement that is often ignored in poor households that cannot afford catastrophic payments [28].

\subsubsection{Measuring CHE Incidence and Intensity}

$E$ is an indicator determining whether $\mathrm{CHE}$ occurred in a household, which is represented as a binary variable:

$$
E_{i}=\left\{\begin{array}{lll}
0 & \text { if } & T_{i} /\left(x_{i}-f(x)\right)<z \\
1 & \text { if } & T_{i} /\left(x_{i}-f(x)\right) \geq z
\end{array}\right\}
$$

where $T$ is the OOP payment for healthcare by household $i, x$ is the total expenditure of the household, $f(x)$ is the food expenditure of a household, and $\mathrm{z}$ is the given catastrophic threshold.

CHE is usually assessed in terms of incidence and intensity. Headcount $(H C)$ is used to measure the incidence of $\mathrm{CHE}$, while overshoot $(O)$ and mean positive overshoot $(M P O)$ are used to measure intensity. HC indicates the percentage of households whose OOP health expenditure, as a fraction of their total non-food expenditures, exceeds the specified threshold $(z)$. When $\mathrm{N}$ represents the sample size, $\mathrm{HC}$ is estimated as follows:

$$
\mathrm{HC}=\frac{1}{N} \sum_{i=1}^{N} E_{i}
$$

The catastrophic payment overshoot $(O)$ describes the average extent to which OOP health expenditure exceeds the chosen threshold of the entire sample. That is to say, it reveals the average CHE severity for all households. $O$ and $O_{i}$ (the household overshoot) are estimated as:

$$
\begin{gathered}
\mathrm{O}=\frac{1}{N} \sum_{i=1}^{N} O_{i} \\
O_{i}=E_{i}\left(\left(T_{i} /\left(x_{i}-f(x)\right)\right)-z\right)
\end{gathered}
$$

The MPO measures the mean overshoot among households with $\mathrm{CHE}$ at the given threshold in the sample, which can be calculated as follows:

$$
\mathrm{MPO}=\frac{O}{H C}
$$

\subsubsection{Regression Analysis on Associated Factors of CHE}

Since incidence $\left(E_{i}\right)$ is a binary variable, logistic regression modeling was applied to estimate the effects of $\mathrm{CII}$ and related factors on the incidence of $\mathrm{CHE}$. In addition, multiple linear regressions were used to analyze the associated factors of $\mathrm{CHE}$ intensity since intensity $\left(O_{i}\right)$ is a continuous variable. Assuming $x_{k}$ is factors related to $\mathrm{CHE}$, and $Y$ indicates the incidence or intensity, the model is shown below:

$$
Y_{i}=\alpha+\sum_{k} \beta_{k} x_{k i}+\varepsilon_{i}
$$


All statistical analysis was performed with Stata software version 14.0 (Stata Corp, College Station, TX, USA), and $p<0.1$ was established as the level of statistical significance. In addition, we calculated the incidence and intensity of CHE of urban and rural households, respectively, based on five thresholds: $20 \%, 30 \%, 40 \%, 50 \%$, and $60 \%$ of CTP, which was done to observe the changes of incidence and intensity at different levels. When we analyzed the determinants of $\mathrm{CHE}$, we used the $40 \%$ threshold in accordance with the WHO definition of CHE.

\section{Results}

\subsection{Characteristics of Urban and Rural Households}

Table 2 shows the description statistics of characteristics of rural and urban households. Among all households included, $54.04 \%$ (1978) were registered as urban and $45.96 \%$ (1682) as rural. The proportion of households with one or more members insured by CII was $49.92 \%$, and the average number of household members having CII was 1.44 . Most (83.06\%) household heads registered as rural reported having a less than lower secondary education, which was much higher in comparison with household heads registered as urban (58.95\%). There were more tertiary educated subjects in urban areas $(17.80 \%)$ compared to rural (2.56\%). Employed household heads in rural areas accounted for $72.59 \%$, which was nearly tripled the proportion of retired (7.79\%) and unemployed (19.62\%). In urban households, almost half of householders were retired or unemployed. The mean household size in rural areas (3.36) is higher than that in urban areas (2.98). It is noted that $76.46 \%$ of rural households had one or more members ( 2.40 on average) with CII, while only $27.35 \%$ of households in urban areas included members covered by CII ( 0.63 on average). Overall, $22.90 \%$ of sampled households reported having members with $\geq 2$ chronic diseases, and there was no significant difference between urban $(23.36 \%)$ and rural $(22.35 \%)$ households. The percentages of households having one or more members $\geq 65$ years of age were $34.36 \%$ and $41.30 \%$ in rural and urban households, respectively. With regard to healthcare utilization, the proportion of households with members having sought outpatient or inpatient care was significantly higher in rural area $(31.45 \%$ and $29.31 \%)$ in comparison with the urban area $(25.78 \%$ and $26.49 \%$ ) Furthermore, the proportions of households with one or more member having sought outpatient and inpatient care from a second-level hospital or above were $14.4 \%$ and $25.08 \%$, respectively. 
Table 2. Characteristics of rural and urban households in Jiangsu Province.

\begin{tabular}{|c|c|c|c|c|}
\hline Variable & Total $N=3660$ & Rural Household $N=1682$ & Urban Household $N=1978$ & $p$-Value \\
\hline Marital Status of Household Head & & & & 0.417 \\
\hline Married & $87.27 \%(3194)$ & $87.75 \%(1476)$ & $86.86 \%(1718)$ & \\
\hline Unmarried (Single, Widowed, Divorced, or Other) & $12.73 \%(466)$ & $12.25 \%(206)$ & $13.14 \%(260)$ & \\
\hline Education Status of Household Head & & & & 0.000 \\
\hline Less than Lower Secondary & $70.03 \%(2563)$ & $83.06 \%(1397)$ & $58.95 \%(1166)$ & \\
\hline Upper Secondary Vocational Training & $19.18 \%(702)$ & $14.39 \%(242)$ & $23.26 \%(460)$ & \\
\hline Tertiary & $10.79 \%(395)$ & $2.56 \%(43)$ & $17.80 \%(352)$ & \\
\hline Employment Status of Household Head & & & & 0.000 \\
\hline Employed & $60.49 \%(2214)$ & $72.59 \%(1221)$ & $50.20 \%(993)$ & \\
\hline Retired & $23.14 \%(847)$ & $7.79 \%(131)$ & $36.20 \%(716)$ & \\
\hline Unemployed & $16.37 \%(599)$ & $19.62 \%(330)$ & $13.60 \%(269)$ & \\
\hline Household Size (Mean) & 3.16 & 3.36 & 2.98 & 0.000 \\
\hline Household CII Status & & & & 0.000 \\
\hline No One Insured & $50.08 \%(1833)$ & $23.54 \%(396)$ & $72.65 \%(1437)$ & \\
\hline One or More Members Insured by CII & $49.92 \%(1827)$ & $76.46 \%(1286)$ & $27.35 \%(541)$ & \\
\hline Number of Household Members Having CII (Mean) & 1.44 & 2.40 & 0.63 & 0.000 \\
\hline Household Income Level & & & & 0.000 \\
\hline$\leq ¥ 30,000$ & $24.23 \%(887)$ & $36.09 \%(607)$ & $14.16 \%(280)$ & \\
\hline$¥ 30,000-50,000$ & $19.86 \%(727)$ & $23.42 \%(394)$ & $16.84 \%(333)$ & \\
\hline$¥ 50,000-78,500$ & $15.90 \%(582)$ & $13.20 \%(222)$ & $18.20 \%(360)$ & \\
\hline$¥ 78,500-100,000$ & $21.07 \%(771)$ & $15.93 \%(268)$ & $25.43 \%(503)$ & \\
\hline$>¥ 100,000$ & $18.93 \%(693)$ & $11.36 \%(191)$ & $25.38 \%(502)$ & \\
\hline Household Members with $\geq 2$ Chronic Diseases & & & & 0.472 \\
\hline All Household Members Have One or No Chronic Disease & $77.10 \%(2822)$ & $77.65 \%(1306)$ & $76.64 \%(1516)$ & \\
\hline Any Member with $\geq 2$ Chronic Diseases & $22.90 \%(838)$ & $22.35 \%(376)$ & $23.36 \%(462)$ & \\
\hline Household Members $>65$ Years Old & & & & 0.000 \\
\hline No One $>65$ Years Old & $61.89 \%(2265)$ & $65.64 \%(1104)$ & $58.70 \%(1161)$ & \\
\hline One or More Members $>65$ Years Old & $38.11 \%(1395)$ & $34.36 \%(578)$ & $41.30 \%(817)$ & \\
\hline Outpatient Utilization Status & & & & 0.000 \\
\hline No One Utilized & $71.61 \%(2621)$ & $68.55 \%(1153)$ & $74.22 \%(1468)$ & \\
\hline One or More Member Utilized & $28.39 \%(1039)$ & $31.45 \%(529)$ & $25.78 \%(510)$ & \\
\hline
\end{tabular}


Table 2. Cont

\begin{tabular}{|c|c|c|c|c|}
\hline Variable & Total $N=3660$ & Rural Household $N=1682$ & Urban Household $N=1978$ & $p$-Value \\
\hline Inpatient Utilization Status & & & & 0.058 \\
\hline No One Utilized & $72.21 \%(2643)$ & $70.69 \%(1189)$ & $73.51 \%(1454)$ & \\
\hline One or More Member Utilized & $27.79 \%(1017)$ & $29.31 \%(493)$ & $26.49 \%(524)$ & \\
\hline Outpatient Service in A High-Level Hospital & & & & 0.104 \\
\hline No One Went to A Second-Level Hospital or Above for Outpatient Treatment & $85.60 \%(3133)$ & $86.62 \%(1457)$ & $84.73 \%(1676)$ & \\
\hline Anyone Went to A Second-Level Hospital or Above for Outpatient Treatment & $14.40 \%(527)$ & $13.38 \%(225)$ & $15.27 \%(302)$ & \\
\hline Inpatient Service in High-Level Hospital & & & & 0.547 \\
\hline No One Went to A Second-Level Hospital or Above for Inpatient Treatment & $74.92 \%(2742)$ & $75.39 \%(1268)$ & $74.52 \%(1474)$ & \\
\hline Anyone Went to A Second-Level Hospital or Above for Inpatient Treatment & $25.08 \%(918)$ & $24.61 \%(414)$ & $25.48 \%(504)$ & \\
\hline
\end{tabular}

Note: CII, critical illness insurance. 


\subsection{CHE Incidence and Intensity in Urban and Rural Households}

Table 3 presents the incidence (headcount) and intensity (overshoot) of CHE. CHE incidence and intensity in sampled households dropped remarkably as the threshold level increased from $20 \%$ to $60 \%$. We observed significantly higher headcount and overshoot at any given threshold in rural households compared with urban households. At the lowest $20 \%$ threshold, households incurring CHE demonstrated the highest incidence $(51.31 \%)$, overshoot $(16.25 \%)$, and MPO $(31.67 \%)$ among rural households. One in five $(20.10 \%)$ rural households experienced catastrophe even at the highest $60 \%$ threshold. Using a widely used threshold of $40 \%$, CHE incidence rates among urban and rural households were $26.54 \%$ and $32.28 \%$, respectively, and the intensity indicates that urban and rural households on average spent $6.46 \%$ (overshoot) and $8.44 \%$ (overshoot), respectively, over the $40 \%$ catastrophic threshold. The MPO for households facing CHE was estimated as $25.25 \%$. The average OOP was $65.25 \%(40 \%+25.25 \%)$ of their total non-food expenditure. The corresponding value was slightly higher in rural $(26.15 \%)$ than in urban $(24.32 \%)$ households.

Table 3. Incidence and intensity of catastrophic health expenditure (CHE_in urban and rural households in Jiangsu Province.

\begin{tabular}{|c|c|c|c|c|c|c|}
\hline & & \multicolumn{5}{|c|}{ Catastrophic Threshold (Share of Non-Food Household Expenditure) } \\
\hline & & $20 \%$ & $30 \%$ & $40 \%$ & $50 \%$ & $60 \%$ \\
\hline \multirow{5}{*}{$\begin{array}{l}\text { All } \\
\text { Households }\end{array}$} & Headcount & $48.09 \%$ & $36.15 \%$ & $29.18 \%$ & $23.74 \%$ & $17.40 \%$ \\
\hline & Overshoot & $14.53 \%$ & $10.52 \%$ & $7.37 \%$ & $4.87 \%$ & $3.04 \%$ \\
\hline & Mean & & & & & \\
\hline & Positive & $30.22 \%$ & $29.10 \%$ & $25.25 \%$ & $20.53 \%$ & $17.45 \%$ \\
\hline & Overshoot & & & & & \\
\hline \multirow{5}{*}{$\begin{array}{l}\text { Urban } \\
\text { Households }\end{array}$} & Headcount & $45.35 \%$ & $33.27 \%$ & $26.54 \%$ & $21.03 \%$ & $15.12 \%$ \\
\hline & Overshoot & $13.07 \%$ & $9.33 \%$ & $6.46 \%$ & $4.23 \%$ & $2.63 \%$ \\
\hline & Mean & & & & & \\
\hline & Positive & $28.82 \%$ & $28.04 \%$ & $24.32 \%$ & $20.11 \%$ & $17.42 \%$ \\
\hline & Overshoot & & & & & \\
\hline \multirow{5}{*}{$\begin{array}{l}\text { Rural } \\
\text { Households }\end{array}$} & Headcount & $51.31 \%$ & $39.54 \%$ & $32.28 \%$ & $26.93 \%$ & $20.10 \%$ \\
\hline & Overshoot & $16.25 \%$ & $11.92 \%$ & $8.44 \%$ & $5.63 \%$ & $3.51 \%$ \\
\hline & Mean & & & & & \\
\hline & Positive & $31.67 \%$ & $30.15 \%$ & $26.15 \%$ & $20.91 \%$ & $17.48 \%$ \\
\hline & Overshoot & & & & & \\
\hline \multirow{4}{*}{ Difference } & Headcount & $0.060^{* * *}$ & $0.063^{* * *}$ & $0.057^{* * *}$ & $0.059^{* * *}$ & $0.050^{* * *}$ \\
\hline & $\mathrm{Sd}$ & 0.017 & 0.016 & 0.015 & 0.014 & 0.013 \\
\hline & Overshoot & $0.032^{* * *}$ & $0.026^{* * *}$ & $0.020^{* * *}$ & $0.014^{* * *}$ & $0.008^{* * *}$ \\
\hline & $\mathrm{Sd}$ & 0.007 & 0.006 & 0.005 & 0.004 & 0.003 \\
\hline
\end{tabular}

Note: Difference is the difference of incidence and intensity between rural and urban households; ${ }^{* * *}$ significant at $1 \%$. SD, standard deviation.

\subsection{Associated Factors of CHE Incidence}

The associated factors of the CHE incidence (at a non-food threshold of $40 \%$ ) are shown in Table 4. Households with any members insured by CII were significantly less likely to experience CHE compared with households having no members insured by $\mathrm{CII}$, but the number of household members with CII did not have any significant effect on CHE incidence. Considering some potential interaction effect, we include an interaction variable of the number of household members having $\mathrm{CII}$ and household members $>65$ years old in the regression model. It showed that in households with $>65$-year-old members, more household members having CII will increase the incidence of CHE significantly $(\mathrm{OR}=1.077,95 \% \mathrm{CI}=(0.986,1.175))$. In addition, household heads with an education level of tertiary were significantly less likely to incur CHE compared to those with a low education level (odds ratio $(\mathrm{OR})=0.723,95 \% \mathrm{CI}=(0.521,1.003)$ ). The results indicate a significant correlation 
between CHE incidence and household size $(\mathrm{OR}=0.933,95 \% \mathrm{CI}=(0.867,1.004))$, which means that $\mathrm{CHE}$ are more likely to occur in small, elderly households. High household income groups had a lower likelihood of CHE. In addition, households with members having $\geq 2$ chronic diseases demonstrated a significantly higher likelihood of CHE $(\mathrm{OR}=2.040,95 \% \mathrm{CI}=(1.694,2.458))$. Healthcare utilization of household members was negatively associated with CHE incidence. Having one or more members that visited hospitals for outpatient or inpatient services significantly increased the likelihood of CHE $(\mathrm{OR}=1.421 ; 1.736,95 \% \mathrm{CI}=(1.154,1.750) ;(1.114,2.704))$. Households with members having ever visited second-level hospitals or above for outpatient or inpatient services had a higher CHE incidence $(\mathrm{OR}=1.270 ; 2.111,95 \% \mathrm{CI}=(0.973,1.656) ;(1.332,3.344))$.

Table 4. Logistic regression on the incidence of CHE (at a non-food expenditure threshold of 40\%).

\begin{tabular}{|c|c|c|c|}
\hline \multirow{2}{*}{ Variables } & \multicolumn{3}{|c|}{ Incidence of $\mathrm{CHE}$} \\
\hline & OR & SD & $95 \% \mathrm{CI}$ \\
\hline $\begin{array}{l}\text { Marital Status of Household Head (Ref: Single, Widowed, } \\
\text { Divorced or Other) }\end{array}$ & 0.948 & 0.102 & $(0.768,1.170)$ \\
\hline \multicolumn{4}{|c|}{ Education Status of Household Head (Ref: Less than Lower Secondary) } \\
\hline Upper Secondary Vocational Training & 0.831 & 0.092 & $(0.669,1.032)$ \\
\hline Tertiary & $0.723 *$ & 0.121 & $(0.521,1.003)$ \\
\hline \multicolumn{4}{|l|}{ Employment Status of Household Head (Ref: Employed) } \\
\hline Retired & 1.107 & 0.126 & $(0.886,1.383)$ \\
\hline Unemployed & 1.068 & 0.121 & $(0.856,1.333)$ \\
\hline Registered Type of Household Head (Ref: Urban) & 0.775 & 0.077 & $(0.638,1.103)$ \\
\hline Household Members $>65$ Years Old (Ref: None) & 1.138 & 0.126 & $(0.916,1.414)$ \\
\hline Household Size & $0.933 *$ & 0.035 & $(0.867,1.004)$ \\
\hline \multicolumn{4}{|l|}{ Household Income Level (Ref: $\leq ¥ 30,000$ ) } \\
\hline$¥ 30,000-50,000$ & $0.315^{* * *}$ & 0.036 & $(0.252,0.395)$ \\
\hline$¥ 50,000-78,500$ & $0.254^{* * *}$ & 0.034 & $(0.196,0.330)$ \\
\hline$¥ 78,500-100,000$ & $0.186^{* * *}$ & 0.025 & $(0.142,0.243)$ \\
\hline$>¥ 100,000$ & $0.091^{* * *}$ & 0.015 & $(0.065,0.127)$ \\
\hline Household Members with $\geq 2$ Chronic Illness (Ref: None) & $2.040 * * *$ & 0.194 & $(1.694,2.458)$ \\
\hline Outpatient Utilization of Household Members (Ref: None) & $1.421 * * *$ & 0.151 & $(1.154,1.750)$ \\
\hline Inpatient Utilization of Household Members (Ref: None) & $1.736 * *$ & 0.393 & $(1.114,2.704)$ \\
\hline Household CII Status (Ref: No One Has CII) & $0.760 *$ & 0.109 & $(0.574,1.006)$ \\
\hline Number of Household Members Having CII & 1.026 & 0.051 & $(0.930,1.132)$ \\
\hline Outpatient Service in High-Level Hospital (Ref: None) & $1.270 *$ & 0.172 & $(0.973,1.656)$ \\
\hline Inpatient Service in High-Level Hospital (Ref: None) & $2.111^{* * *}$ & 0.496 & $(1.332,3.344)$ \\
\hline Household Members $>65$ Years Old $\times$ Number of Household & & & \\
\hline $\begin{array}{l}\text { Members Having CII (Ref: Number Of Members Having CII } \\
\text { in A Household without Members over } 65 \text { ) }\end{array}$ & $1.077 *$ & 0.048 & $(0.986,1.175)$ \\
\hline
\end{tabular}

Note: ${ }^{*}$ significant at $10 \%,{ }^{* *}$ significant at $5 \%,{ }^{* * *}$ significant at $1 \%$. CHE, catastrophic health expenditure; $\mathrm{CI}$, confidence interval; $\mathrm{CII}$, critical illness insurance; $\mathrm{OR}$, odds ratio; $\mathrm{SD}$, standard deviation.

\subsection{Associated Factors of CHE Intensity}

Table 5 shows the multiple linear regression results for CHE intensity. We found a mixed impact of the CII status of household on CHE intensity. Having one or more household members with CII was positively associated with $\mathrm{CHE}$ intensity compared with having no CII-covered household members. However, as the number of household members insured by CII increased, the intensity of CHE significantly decreased. The results also revealed a statistical correlation between marital and education status of household heads and CHE intensity. Unmarried or individuals having a medium-level education (upper secondary and vocational training) were positively associated with CHE intensity. Household head employment status was also significantly correlated with CHE intensity. Specifically, retired or unemployed status significantly increased CHE intensity in comparison with the employed. 
Although living in rural areas was associated with a lower likelihood of CHE in Table 4, the intensity of CHE was significantly higher in rural households compared to urban households. The presence of household members $>65$ years old was a significant contributor to $\mathrm{CHE}$ intensity. The interaction variable of household members $>65$ years old and number of household members having CII was negatively associated with CHE intensity. In addition, the association between household size and $\mathrm{CHE}$ intensity was significantly positive. Household income levels negatively associated with CHE intensity, and this effect was estimated to be greater among high-income groups. Households with any member with at least two chronic diseases significantly increased CHE intensity.

Table 5. Multiple linear regression on the intensity of CHE (at a non-food expenditure threshold of $40 \%)$.

\begin{tabular}{|c|c|c|c|}
\hline \multirow{2}{*}{ Variables } & \multicolumn{3}{|c|}{ Intensity of CHE } \\
\hline & Coefficient & SD & $95 \% \mathrm{CI}$ \\
\hline $\begin{array}{l}\text { Marital Status of Household Head (Ref: Single, Widowed, } \\
\text { Divorced, or Other) }\end{array}$ & $0.046^{* * *}$ & 0.006 & $(0.034,0.058)$ \\
\hline \multicolumn{4}{|c|}{ Education Status of Household Head (Ref: Less than Lower Secondary) } \\
\hline Upper Secondary Vocational Training & 0.011 * & 0.006 & $(-0.001,0.023)$ \\
\hline Tertiary & 0.009 & 0.008 & $(-0.007,0.025)$ \\
\hline \multicolumn{4}{|l|}{ Employment Status of Household Head (Ref: Employed) } \\
\hline Retired & $0.019 * * *$ & 0.006 & $(0.007,0.032)$ \\
\hline Unemployed & $0.034^{* * *}$ & 0.007 & $(0.021,0.047)$ \\
\hline Registered Type of Household Head (Ref: Urban) & $0.009 *$ & 0.005 & $(-0.001,0.020)$ \\
\hline Household Members > 65 Years Old (Ref: None) & $0.045^{* * *}$ & 0.006 & $(0.033,0.058)$ \\
\hline Household Size & $0.005^{* *}$ & 0.002 & $(0.001,0.009)$ \\
\hline \multicolumn{4}{|l|}{ Household Income Level (Ref: $\leq ¥ 30,000$ ) } \\
\hline$¥ 30,000-50,000$ & $-0.052 * * *$ & 0.007 & $(-0.065,0.039)$ \\
\hline$¥ 50,000-78,500$ & $-0.068^{* * *}$ & 0.008 & $(-0.083,-0.053)$ \\
\hline$¥ 78,500-100,000$ & $-0.080^{* * *}$ & 0.007 & $(-0.095,-0.066)$ \\
\hline$>¥ 100,000$ & $-0.107^{* * *}$ & 0.008 & $(-0.124,-0.091)$ \\
\hline Household Members with $\geq 2$ Chronic Illness (Ref: None) & $0.041^{* * *}$ & 0.006 & $(0.030,0.052)$ \\
\hline Outpatient Utilization of Household Member (Ref: None) & $0.019 * * *$ & 0.006 & $(0.006,0.031)$ \\
\hline Inpatient Utilization of Household Member (Ref: None) & $0.049 * * *$ & 0.014 & $(0.022,0.077)$ \\
\hline Household CII Status (Ref: No One Has CII) & $0.025^{* * *}$ & 0.008 & $(0.010,0.041)$ \\
\hline Number of Household Members Having CII & $-0.005^{* *}$ & 0.003 & $(-0.010,-0.000)$ \\
\hline Outpatient Service in High-Level Hospital (Ref: None) & 0.003 & 0.008 & $(-0.012,0.019)$ \\
\hline Inpatient Service in High-Level Hospital (Ref: None) & $0.025 *$ & 0.014 & $(-0.003,0.054)$ \\
\hline Household Members $>65$ Years Old $\times$ Number of & & & \\
\hline $\begin{array}{l}\text { Household Members Having CII (Ref: Number of Members } \\
\text { Having CII In A Household without Members Over 65) }\end{array}$ & $-0.006 * *$ & 0.003 & $(-0.011,-0.001)$ \\
\hline
\end{tabular}

Note: ${ }^{*}$ significant at $10 \%,{ }^{* *}$ significant at $5 \%, * *$ significant at $1 \%$. CHE, catastrophic health expenditure; $\mathrm{CI}$, confidence interval; CII, critical illness insurance; SD, standard deviation.

Healthcare utilization of household members was positively correlated with CHE intensity, which means households with any member that sought outpatient or inpatient services had a significantly higher intensity of CHE. Furthermore, CHE intensity significantly increased when household members had gone to the second-level hospitals or above for inpatient treatment. However, there was no association with CHE intensity when members in a household sought outpatient services in high-level hospitals.

\section{Discussion}

Implementing CII is an important step in the Chinese government's efforts to reduce CHE and alleviate household economic burden due to illness. As China's population rapidly ages, more residents 
are suffering from serious diseases, and households are faced with heavy financial burdens. Following nationwide CII implementation, it is essential to study the effect on household financial risks of diseases. Our study used the latest data to calculate the incidence and extent of CHE among rural and urban households and estimate the effect of $\mathrm{CII}$ and other factors on CHE incidence and intensity.

Among the 3660 included households in Jiangsu Province, the proportion with any members insured by CII in rural areas was higher than that in urban areas $(76.46 \%$ vs. $27.35 \%)$, which demonstrates the inadequate and imbalanced coverage of CII. The proportion of all sampled households facing CHE at OOP $\geq 40 \%$ of non-food expenditure was $29.18 \%$, which was greater than the proportion $(16.5 \%)$ reported in another study based on 2015 national data [29]. In Table 3, The CHE incidence (Headcount) and intensity (Overshoot) of rural households were significantly higher than those of urban households, irrespective of the threshold used. This result is similar to a study conducted in three cities in eastern China [30]. Moreover, we found the CHE of rural households was $>66.15 \%$ of their non-subsistence expenditure (MPO). These findings in regard to CHE incidence (Headcount) and intensity (Overshoot) of households in rural and urban areas indicate that households, especially in rural areas, are still vulnerable to high medical care costs. Lower income level and the absence of social security in rural areas are among the possible causes. Thus, the government should implement more measures focused on rural households to improve the social security system and reduce their CHE.

Regarding the associated factors of CHE in Jiangsu Province, we found that households with a low education householder, lower household income, members with $\geq 2$ chronic diseases, and utilizing outpatient and inpatient services have a higher likelihood of CHE incidence, which is in accordance with other studies [3,31-34]. The above factors are also associated with a higher intensity of CHE. The coefficient of the interaction variable of household members $>65$ years old and number of household members having CII was $-0.006(p<0.05)$, which indicates that, compared to households without members $>65$ years old, the number of members covered by $\mathrm{CII}$ in households with members $>65$ years old have stronger negative effect on the intensity of CHE. With regard to CHE incidence, the effect of the interaction variable was significantly positive, which means that households with $>65$-year-old members are more likely to have CHE when the number of CII-insured members in the household increases. The CII seems to provide protection for households having members $>65$ years old who are also the insured of CII from high intensity of CHE but fail to reduce the occurrence of CHE among households. We supposed that more CII patients in a household might have a higher likelihood of having expensive diseases in that household. Also, most of the members insured by CII in a household may be the elderly. They are easily suffered from diseases and are vulnerable to higher healthcare expenses. Therefore, it is necessary to further focus policy efforts on elderly and impoverished households, such as increasing welfare subsidies or extending medical assistance programs to enhance financial protection and reduce CHE. Previous reports described significant associations between the type of healthcare facility and CHE $[28,35]$. Our study also found that seeking inpatient services in second-level hospitals or above increased CHE incidence and intensity, which suggests that higher medical costs of high-level hospitals and hospitalization may result in more catastrophic health expenses. In addition, chronic diseases cause both suffering to patients and catastrophic financial burden to households, as demonstrated in several studies $[29,31-34,36]$. Therefore, increasing the medical insurance level of patients with chronic diseases and improving chronic disease management could reduce household CHE and provide protection against medical economic risks.

Rural registration had no significant association with CHE incidence, contrary to some existing studies [29,30], but had significantly higher CHE intensity compared with urban households. A possible explanation is that there may be non-use of needed healthcare services by patients in rural households because of low income [37]. However, rural patients utilizing health services tend to go to more expensive high-level hospitals because they offer advanced medical equipment and technology compared to first-level hospitals. Therefore, OOP of rural households may far exceed their non-food expenditure [38]. The government should take the reimbursement level of rural residents and improvement of first-level hospital services into account. Household size means the number of 
persons living together in one household. The result of our study that household size was negatively associated with the likelihood of CHE is in agreement with previous reports [29,39,40]. However, several published studies pointed out that large household size is significantly associated with high CHE [35,41]. We found a slightly positive correlation between household size and CHE intensity. These findings indicate that larger families protect against CHE incidence but not intensity. As the characteristic result in Table 1 indicated, rural household size is significantly higher than urban. Larger families are usually found in Chinese rural areas. In China, a nuclear family, consisting of a married couple and their unmarried children, is the mainstream form of family structure in urban areas. While in rural areas, there are more households with three or four generations living together, which are called a stem family or joint family. And generally, the proportion of the elderly in rural households is higher than that in urban areas because the majority of the elderly are employed in agriculture, and they are used to living in rural areas. The young and middle-aged tend to go to cities for better employment and live there. Although larger families may have a good economic ability to reduce the risk of $\mathrm{CHE}$, they are more likely to include more elderly members or children who are susceptible to illness and incur higher costs [30].

Previous studies concerning the effect of $\mathrm{CII}$ on relieving financial burden have yielded mixed results. Some studies held the view that the effect is limited from the perspective of CII reimbursement level $[22,23,42]$, while other studies indicated that economic burden decreased after CII implementation $[3,43,44]$. In our study, a household with members having CII was a factor to protect households from CHE incidence, but it significantly increased CHE intensity. The number of household members insured by CII did not affect the incidence at a significant level, but this factor significantly decreased the intensity of CHE. A possible explanation is that having CII actually improves households' capacity to resist economic risk due to critical diseases, and therefore, significantly decreased CHE incidence. However, CII implementation also induced residents' demands for medical services [23], which could lead to higher healthcare expenses, even including uncovered medical expenses that are not on the CII list. Therefore, once CHE occurs in a household, the intensity will be greater, especially in lower-income households. As the number of the insured by CII in a household increased, the association of CII with incidence became insignificant. Instead, households with more CII-covered members decreased CHE intensity.

The main purpose of $\mathrm{CII}$ is to provide protection against CHE; however, our study showed that this objective has not been fully achieved in Jiangsu Province. In view of the possible causes listed above, policy efforts should focus on the following aspects. First, strategies should be developed to promote the inclusion of more households in CII to effectively decrease household CHE incidence. At the same time, it is necessary for the government to establish a dynamic reimbursement list of CII to expand coverage and reduce uncovered medical expenses. Second, due to the significant effect of the number of CII-covered household members on CHE intensity, the CII coverage rate in Jiangsu province should be continually increased to better relieve economic burden associated with disease. Third, to better exert the protective effect of CII, some medical cost control mechanisms should be established to reduce irrational increases of medical expenses exceeding actual needs. In addition, rural households are in urgent need of policy support because of the higher incidence and intensity of $\mathrm{CHE}$, lower-income, and less social security. Therefore, the government should properly increase the reimbursement rate or reduce the deductible line of CII in rural areas to further alleviate household economic burden of diseases.

Some limitations of this study must be noted here. (1) We calculated household medical expenses, excluding indirect expenses (e.g., transport, food, accommodation costs, etc.) for patients and companions, which is reported to account for a fair proportion of total OOP. This conclusion may lead to an underestimation of CHE. (2) Due to limited access to data, our study used a sub-sample of NHSS (2018) data from Jiangsu Province, which may be not nationally representative. However, Jiangsu Province is a relatively developed area and is typical in the implementation of CII among 31 provinces surveyed. (3) We evaluated the effect of CII on CHE by measuring the incidence and intensity; we did 
not focus on specific OOP and the actual reimbursement ratio because of a lack of data. Further studies will be done in the future.

\section{Conclusions}

To the best of our knowledge, some theoretical studies researching the implementation effect of $\mathrm{CII}$ in China mainly focused on describing and comparing the design and development of the program policy. Due to a short period of time since broad CII implementation and lack of empirical data, few existing studies provide strong empirical evidence on the effect of CII on CHE. Our study, basing on Chinese latest and authoritative data of the representative region, not only reveals urban-rural discrepancies in the incidence and intensity of CHE but also show the mixed effect of CII and some other associated factors on CHE. More government measures focusing on rural households should be implemented to reduce their catastrophic medical expenses. Policy adjustments such as a dynamic CII list, medical cost control mechanisms, broader CII coverage, or improved reimbursement levels should be developed to provide solid protection for Chinese households against financial medical risk. Additionally, other socioeconomic factors significantly affecting $\mathrm{CHE}$ indicate that policies aimed at reducing CHE should address the socioeconomic factors of healthcare outcomes among urban and rural households. Our study clarifies the implementation effect of its CII on financial risk protection in Jiangsu Province, and it also provides reference and guidance for reforming China's healthcare insurance.

Author Contributions: Conceptualization, A.L., Y.S. and Z.W.; methodology, A.L., Y.S. and Z.W.; validation, A.L., Y.S. and X.Y.; formal analysis, A.L., X.Y. and Z.W.; investigation, A.L., Y.S. and X.Y.; data curation, Z.W.; writing—original draft preparation, A.L.; writing—review and editing, A.L., Y.S. and Z.W.; supervision, Z.W.; All authors read and approved the final manuscript.

Funding: This research was funded by the National Office for Philosophy and Social Sciences of China (No.18BGL243). The funding bodies were not involved in the design of the study, or data collection, analysis, and interpretation or in writing the manuscript.

Acknowledgments: We would like to acknowledge the Chinese National Health Commission and the local Health Commission of Jiangsu province for their cooperation. We would also like to thank all study participants for their time to be interviewed.

Conflicts of Interest: The authors declare no conflict of interest.

$\begin{array}{ll}\text { Abbreviations } \\ \text { BMI } & \text { basic medical insurance } \\ \text { CHE } & \text { catastrophic health expenditure; } \\ \text { CII } & \text { Critical Illness Insurance } \\ \text { CTP } & \text { capacity to pay } \\ \text { MPO } & \text { mean positive overshoot } \\ \text { OOP } & \text { out-of-pocket healthcare payments } \\ \text { NHSS } & \text { National Health Service Study } \\ \text { UHC } & \text { universal health coverage } \\ \text { NRCMS } & \text { The new rural cooperative medical scheme } \\ \text { URMI } & \text { the urban resident medical insurance } \\ \text { WHO } & \text { World Health Organization. }\end{array}$

\section{References}

1. World Health Organization. World Health Statistics 2018: Monitoring Health for the Sdgs, Sustainable Development Goals; World Health Organization: Geneva, Switzerland; Available online: http://www.who.int/iris/handle/ 10665/272596 (accessed on 17 May 2018).

2. Li, H.; Jiang, L. Catastrophic medical insurance in China. Lancet 2017, 390, 1724-1725. [CrossRef] 
3. Zhao, S.; Zhao, S.W.; Zhang, X.Y.; Dai, W.; Ding, Y.; Chen, J.; Fang, P. Effect of the catastrophic medical insurance on household catastrophic health expenditure: Evidence from China. Gac. Sanit. 2019. [CrossRef] [PubMed]

4. Zhou, M.G.; Wang, H.; Zeng, X.; Yin, P.; Zhu, J.; Chen, W. Mortality, morbidity, and risk factors in China and its provinces, 1990-2017: A systematic analysis for the Global Burden of Disease Study 2017. Lancet 2019, 394, 1145-1158. [CrossRef]

5. People's Daily. The 8th U.S.-China Health Forum. Available online: http://www.jksb.com.cn/html/2018/ activityreport_1014/129673.html (accessed on 14 October 2018).

6. National Bureau of Statistics. Statistical Bulletin on Chinese National Economic and Social Development 2016. National Bureau of Statistics. Available online: http://www.stats.gov.cn/tjsj/zxfb/201702/t20170228_ 1467424.html (accessed on 28 February 2017).

7. Zhang, L.; Li, S.; Yi, H.; Li, M.; Ding, Y. Correlation Between New Cooperative Medical Scheme Policy Design and Catastrophic Medical Payment: Evidence from 25 Counties in Rural China. Asia Pac. J. Public Health 2016, 28, 26-38. [CrossRef] [PubMed]

8. Zhou, Y.J.; Tang, Y.X.; Zhang, Q.; Qiu, P.Y.; Zhang, Q. Catastrophic Health Expenditure before and after Compensations from the New Rural Cooperative Medical Scheme in Rural Zigong of Sichuan Province. J. Sichuan Univ. (Med. Sci. Ed.) 2016, 47, 768-771.

9. Gao, G.Y.; Ma, C.Y.; Hu, X.Y.; Yang, X.; Duan, T.; Jia, J.R. Evaluation on the Effect of the Catastrophic Medical Expenditure Insurance for Rural Residents on Alleviating Catastrophic Health Expenditure. Soc. Secur. Stud. 2017, 02, 69-76.

10. National Development and Reform Commission; National Health and Family Planning Commission; Ministry of Finance; Ministry of Human Resources and Social Security; Ministry of Civil Affairs; China Insurance Regulatory Commission. Guidance on the Implementation of Catastrophic Diseases Insurance for Urban and Rural Residents. 2012. Available online: http://www.ndrc.gov.cn/zcfb/zcfbtz/201208/t20120830_502833.html (accessed on 24 August 2012).

11. The Central People's Government of the People's Republic of China. Report on the Work of the Government 2019. State Council of China. Available online: http://www.gov.cn/gongbao/content/2019/content_5377101. htm (accessed on 5 March 2019).

12. Xu, K.; Evans, D.B.; Kawabata, K.; Zeramdini, R.; Klavus, J.; Murray, C.J. Household catastrophic health expenditure: A multicountry analysis. Lancet 2003, 362, 111-117. [CrossRef]

13. Yang, T.; Chu, J.; Zhou, C.; Medina, A.; Li, C.; Jiang, S.; Zheng, W.; Sun, L.; Liu, J. Catastrophic health expenditure: A comparative analysis of empty-nest and non-empty-nest households with seniors in Shandong, China. BMJ Open 2016, 6, e010992. [CrossRef]

14. Barros, A.J.; Bastos, J.L.; Dâmaso, A.H. Catastrophic spending on health care in Brazil: Private health insurance does not seem to be the solution. Cad. Saude Publica 2011, 27, 254-262. [CrossRef]

15. Okoroh, J.; Essoun, S.; Seddoh, A.; Harris, H.; Weissman, J.S.; Dsane-Selby, L.; Riviello, R. Evaluating the impact of the national health insurance scheme of Ghana on out of pocket expenditures: A systematic review. BMC Health Serv. Res. 2018, 18, 426. [CrossRef]

16. Xie, B.; Huo, M.; Wang, Z.; Chen, Y.; Fu, R.; Liu, M.; Meng, Q. Impact of the New Cooperative Medical Scheme on the trend of catastrophic health expenditure in Chinese rural households: Results from nationally representative surveys from 2003 to 2013. BMJ Open 2018, 8, e019442. [CrossRef] [PubMed]

17. Guo, N.; Iversen, T.; Lu, M.; Wang, J.; Shi, L. Does the new cooperative medical scheme reduce inequality in catastrophic health expenditure in rural China? BMC Health Serv. Res. 2016, 16, 653. [CrossRef] [PubMed]

18. Wang, W. Discussion on Financing Mechanism and Reimbursing Policy of Critical Illness Insurance:Based on the Comparison of Pilot Schemes from 25 Provinces of China. J. Huazhong Norm. Univ. (Humanit. Soc. Sci.) 2014, 53, 16-22.

19. Fu, X.; Yang, S.; Wang, Z. Policy Evolution and Reflection on the Catastrophic Medical Insurance for Urban and Rural Residents. Chin. Health Econ. 2019, 38, 13-15.

20. Sang, X.; Wei, G.; Chen, J.; Han, S.; Shi, L. Implementation and Improvement of Critical Illness Insurance for Urban and Rural Residents. Chin. Pharm. Aff. 2016, 30, 1183-1189.

21. Luo, X.L. Study the Performance Evaluation and Policy Suggestions of Urban and Rural Residents' Critical Illness Insurance-Take Four Pilot Areas in Jiangsu Province as an Example. Master's Thesis, Nanjing University, Nanjing, China, 2016. 
22. Fang, P.; Pan, Z.; Zhang, X.; Bai, X.; Gong, Y.; Yin, X. The effect of critical illness insurance in China. Medicine 2018, 97, e11362. [CrossRef]

23. Gong, F.X. The Researches of Impact of Critical Diseases Insurance on the Patient's Health Service Utilization and Economic Burdens. Master's Thesis, Huazhong University of Science and Technology, Wuhan, China, 2018.

24. World Health Organization. The World Health Report: Research for Universal Health Coverage; World Health Organization: Geneva, Switzerland, 2013.

25. National Bureau of Statistics. Sixth National Health Service Statistical Survey System; National Bureau of Statistics: Beijing, China. Available online: http://www.stats.gov.cn/tjfw/bmdcxmsp/bmzd/201809/t20180905_ 1621098.html (accessed on 5 September 2018).

26. Center for Health Statistics and Information. An Analysis Report of National Health Services Survey in China. Available online: http://www.nhc.gov.cn/mohwsbwstjxxzx/s8211/201009/49165.shtml (accessed on 21 September 2010.

27. World Health Organization. Department of health systems financing (2005). Designing Health Financing Systems to Reduce Catastrophic Health Expenditure; Technical briefs for policy makers; World Health Organization: Geneva, Switzerland, 2005; Volume 2.

28. Wang, Z.; Li, X.; Chen, M. Catastrophic health expenditures and its inequality in elderly households with chronic disease patients in China. Int. J. Equity. Health 2015, 14, 8. [CrossRef]

29. Xu, W.; Chu, F. Study on Catastrophic Health Expenditure Level and Influencing Factors-An Analysis Based on CHARLS Data. Soc. Secur. Stud. 2018, 60, 64-72.

30. Li, X.; Shen, J.; Lu, J.; Wang, Y.; Sun, M.; Li, C.; Chang, F.; Hao, M. Household catastrophic medical expenses in eastern China: Determinants and policy implications. BMC Health Serv. Res. 2013, 13, 506. [CrossRef]

31. Kronenberg, C.; Barros, P.P. Catastrophic healthcare expenditure-drivers and protection: The Portuguese case. Health Policy 2014, 115, 44-51. [CrossRef]

32. Liu, Y.; Ren, R. Catastrophic Health Expenditure and Its Impact. Chin. Health Econ. 2010, 29, 37-39.

33. Sun, Y.; Yan, Y.; Xue, Q.; Gao, J. Diabetes-related household catastrophic healthcare expenditure and its income-related inequality in Shaanxi province: A decomposition analysis. Chin. J. Public Health 2018, 34, 1143-1147.

34. Li, X.; Tang, R. A study on the status and influencing factors of catastrophic health expenditure of rural households in Yinchuan. Chin. Prim. Health Care 2017, 31, 1-3.

35. Atake, E.H.; Amendah, D.D. Porous safety net: Catastrophic health expenditure and its determinants among insured households in Togo. BMC Health Serv. Res. 2018, 18, 175. [CrossRef]

36. Wu, Q.; Li, Y.; Xu, L.; Hao, Y. Effect analysis on universal insurance coverage to reduce the incidence of catastrophic health expenditure in China. Chin. J. Health Policy 2012, 5, 62-66.

37. Li, Y.; Wu, Q.; Liu, C.; Kang, Z.; Xie, X.; Yin, H.; Jiao, M.; Liu, G.; Hao, Y.; Ning, N. Catastrophic health expenditure and rural household impoverishment in China: What role does the new cooperative health insurance scheme play? PLoS ONE 2014, 9, e93253. [CrossRef]

38. Weraphong, J.; Pannarunothai, S.; Luxananun, T.; Junsri, N.; Deesawatsripetch, S. Catastrophic health expenditure in an urban city: Seven years after universal coverage policy in Thailand. S. Asian J. Trop. Med. Public Health 2013, 44, 124-136.

39. Buigut, S.; Ettarh, R.; Amendah, D.D. Catastrophic health expenditure and its determinants in Kenya slum communities. Int. J. Equity Health 2015, 14, 46. [CrossRef]

40. Zhang, W.; Li, G. Study on catastrophic health expenditure of families with old people and its influencing factors. J. Shanghai Jiaotong Univ. (Med. Sci.) 2015, 35, 432-436.

41. Brinda, E.M.; Andrés, R.A.; Enemark, U. Correlates of out-of-pocket and catastrophic health expenditures in Tanzania: Results from a national household survey. BMC Int. Health Hum. Rights 2014, 14, 5.

42. Xu, J.Q.; Zheng, J.; Jing, Q.; Li, J.; Xu, L. Distribution and effect evaluation of 20 kinds of critical illness insurance compensation for new rural cooperative medical system in a city of Shandong Province. Chin. J. Health Stat. 2016, 33, 81-84, 87. 
43. Mao, Y.; Zhu, B.; Liu, J.L. Evaluation on the Catastrophic Medical Insurance Policy in China: Based on Empirical Research of Xunyi County. Chin. Health Econ. 2015, 34, 10-14.

44. Jiang, J.; Chen, S.; Xin, Y.; Wang, X.; Zeng, L.; Zhong, Z.; Xiang, L. Does the critical illness insurance reduce patients' financial burden and benefit the poor more: A comprehensive evaluation in rural area of China. J. Med. Econ. 2019, 22, 455-463. [CrossRef] [PubMed]

(C) 2019 by the authors. Licensee MDPI, Basel, Switzerland. This article is an open access article distributed under the terms and conditions of the Creative Commons Attribution (CC BY) license (http://creativecommons.org/licenses/by/4.0/). 